\title{
The association of cardio-metabolic risk factors and history of falling in men with osteosarcopenia: a cross-sectional analysis of Bushehr Elderly Health (BEH) program
}

Noushin Fahimfar ${ }^{1}$, Shakiba Yousefi', Sima Noorali', Safoora Gharibzadeh², Mahnaz Sanjari', Kazem Khalagi', Ahmad Mehri ${ }^{3}$, Gita Shafiee ${ }^{4}$, Ramin Heshmat ${ }^{4}$, Iraj Nabipour ${ }^{5}$, Azam Amini ${ }^{6}$, Amirhossein Darabi ${ }^{7}$, Gholamreza Heidari $^{8}$, Bagher Larijani ${ }^{9}$ and Afshin Ostovar ${ }^{1 *}$

\begin{abstract}
Background: Osteosarcopenia, defined as sarcopenia plus osteopenia/osteoporosis, may increase the risk of fractures and affects morbidity and mortality in the older population. Falling is also common in the elderly and increases the risk of fractures and mortality. We examined the association of cardio-metabolic risk factors with a history of falling in osteosarcopenic men.
\end{abstract}

Methods: We used the baseline data of the Bushehr Elderly Health (BEH) program. Osteosarcopenia was defined as having both sarcopenia (reduced skeletal muscle mass plus low physical performance and/or low muscle strength) and osteopenia/osteoporosis (T-score $\leq-1.0$ ). Falling was defined as a self-reported history of an unintentional down on the ground during the previous year before the study. We used logistic regression analysis to estimate the adjusted odds ratio (AOR) with a 95\% Confidence Interval (CI) to quantify the associations.

Results: All elderly men diagnosed with osteosarcopenia $(n=341)$, with a mean age of $73.3( \pm 7.4)$ years, were included. Almost 50(14.7\%) participants reported falling. Age showed a positive association with falling (AOR: 1.09, 95\%Cl: 1.04-1.14). An increase of $10 \mathrm{mmHg}$ in systolic blood pressure(SBP), reduces the odds of falling by 26\%(AOR:0.74, 95\%Cl:0.62-0.89), while a positive association was detected for fasting plasma glucose (FPG), as $10 \mathrm{mg} /$ $\mathrm{dl}$ increase in the $F P G$, raises the chance of falling by $14 \%(A O R=1.14,95 \% \mathrm{Cl}: 1.06,1.23)$. Hypertriglyceridemia was inversely associated with falling ( $\mathrm{AOR}=0.33,95 \% \mathrm{Cl}: 0.12,0.89$ ).

Conclusions: Falling is a major public health problem in rapidly aging countries, especially in individuals with a higher risk of fragility fractures. Older age-raised fasting plasma glucose and low SBP are associated with falling in osteosarcopenic patients.

Considering the higher risk of fracture in osteosarcopenic men, comprehensive strategies are needed to prevent fallrelated injuries in this high-risk population.

Keywords: Osteosarcopenia, Falling, Elderly, Iran, Cardio-metabolic, Risk factor

\footnotetext{
*Correspondence: aostovar@tums.ac.ir

1 Osteoporosis Research Center, Endocrinology and Metabolism Clinical

Sciences Institute, Tehran University of Medical Sciences, Tehran, Iran

Full list of author information is available at the end of the article
}

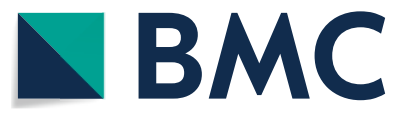

(c) The Author(s) 2022. Open Access This article is licensed under a Creative Commons Attribution 4.0 International License, which permits use, sharing, adaptation, distribution and reproduction in any medium or format, as long as you give appropriate credit to the original author(s) and the source, provide a link to the Creative Commons licence, and indicate if changes were made. The images or other third party material in this article are included in the article's Creative Commons licence, unless indicated otherwise in a credit line to the material. If material is not included in the article's Creative Commons licence and your intended use is not permitted by statutory regulation or exceeds the permitted use, you will need to obtain permission directly from the copyright holder. To view a copy of this licence, visit http://creativecommons.org/licenses/by/4.0/. The Creative Commons Public Domain Dedication waiver (http://creativeco mmons.org/publicdomain/zero/1.0/) applies to the data made available in this article, unless otherwise stated in a credit line to the data. 


\section{Background}

Osteopenia/osteoporosis, characterized by low bone mass, together with sarcopenia, characterized by low muscle mass and function, form the new geriatric syndrome, osteosarcopenia [1], that impose a significant burden on the quality of life among the elderly population and a high cost to health systems worldwide [2].

There is a limited number of studies reporting the epidemiology of osteosarcopenia [3]. In Korea, the prevalence of osteosarcopenia in hip fracture patients aged over 60 years was $27.2 \%$, with a 1.8 times higher mortality rate compared to the non-osteosarcopenic individuals [4]. A higher rate was reported from Australia, where it was $40 \%$ among a population with a mean age of 80.4 years [5]. The prevalence of osteosarcopenia was recently reported as $34 \%$ among elderly aged $\geq 60$ years in Iran [6].

Both bone and muscle mass deterioration share common risk factors in osteosarcopenia [7]. The main risk factors include: 1) mechanical forces, as physical activity has preserved a role for bone and muscle, and inactivity leads to atrophy of both tissues 2) biochemical factors such as hormones include sex hormones, vitamin D, and other factors secreted by muscle and bone, 3) genetic factors, 4) lifestyle behaviors like low vitamin $\mathrm{D}$ and protein diet $[3,8]$.

As a coexistence of two musculoskeletal diseases that are strongly associated with frailty, falls, fractures, hospitalizations, and mortality, osteosarcopenia causes a higher risk of falling and fracture $[9,10]$. As noted in previous studies, sarco-osteoporosis had 3.5 times more fracture risk than those without osteoporosis and sarcopenia [11]. Fall is defined as unintentional down on the ground or lower level without any secondary reasons or external forces. It causes significant injuries that are major health problems in the elderly and contributes significantly to morbidity and mortality and imposes high direct and indirect health-related costs $[12,13]$. Many risk factors are reported for falls such as age, chronic medical condition, multiple medication use, depression, and cognition impairment. In some studies, the metabolic syndrome had significantly associated with falls [14].

According to the WHO, both genders are at risk for falls, while worldwide, men sustain higher mortality rates and DALYs lost. The higher levels of risk-taking behaviors may be one of the possible explanations of the higher burden detected among men [15].

For many years, osteoporosis has been considered a female gender disease, and male osteoporosis, as a neglected condition, face greater under-diagnosis and under-treatment and deserves more attention [16]. Although osteoporosis is more prevalent in women, some document showed that osteoporosis-related mortality and morbidity rates are higher in men; also with the lower lifetime risk of hip fracture in men, they are twice as likely to die after a hip fracture [17].

Some documents proposed the link between osteoporosis, sarcopenia, and osteosarcopenia with cardio-metabolic risk factors [6, 18-20]. Considering the reasons including 1-the high prevalence of osteosarcopenia in the male elderly population in Iran (33.8\%), which puts them at a higher risk of falling (mainly related to the muscle component) and fractures (related mostly to the bone loss), 2-a higher rate of mortality in men due to the falling, and 3-a lower rate of timely diagnosis and treatment of osteoporosis in men, we examined the association between cardio-metabolic risk factors and history of falling in osteosarcopenic men, aged over 60-years living in Bushehr, Iran.

\section{Materials and methods Study population}

This is a cross-sectional study that was conducted within the framework of the Bushehr Elderly Health (BEH) program. The $\mathrm{BEH}$ program is a prospective, population-based cohort study being conducted since 2013 in Bushehr, southern Iran. The study sample was derived from the elderly urban population. A total of 2426 elderly aged 60 years old and over participated in Stage II of the study which was aimed to investigate musculoskeletal health, cognitive function, and their related risk factors [21]. The cohort study was approved by the Research Ethics Committee of both Bushehr University of Medical Sciences, and Endocrinology and Metabolism Research Institute of Tehran University of Medical Sciences, in accordance with the ethical guidelines outlined in the 1975 Helsinki Declaration.Written informed consents were obtained from all individuals included in the study, after a brief explanation of the study objectives and protocols.

\section{Data collection}

The dual X-ray absorptiometry method was used to measure body composition, muscle mass, and bone mineral density (DXA, Discovery WI, Hologic, Inc., USA). Using a digital dynamometer, muscle strength was measured three times for each hand by handgrip strength. The maximum grip strength was calculated by averaging the highest measurement from both hands. Walking speed $(\mathrm{m} / \mathrm{s})$ on a $4.57 \mathrm{~m}$ course was considered as an objective measure of physical performance.

Clinical risk factors were collected in the $\mathrm{BEH}$ program, using a valid questionnaire with several parts 
that addressed sociodemographic status, lifestyle behaviors, past medical history, history of falling, drug history, in addition to mental and functional health. The participants underwent a physical examination to collect information on anthropometric measures, blood pressure, gait speed, and handgrip strength. The weight and height were measured by a digital scale and a fixed stadiometer, wearing light clothing and without shoes. Systolic (SBP) and diastolic (DBP) were measured twice on the right arm, after $15 \mathrm{~min}$ of rest in the sitting position using a mercury sphygmomanometer. After overnight fasting, venous blood samples were taken, and lipid profile and blood glucose were measured by the enzymatic colorimetric method. The details for the measurements and examinations were described elsewhere [21].

\section{Definition of terms}

The study population consisted of individuals who had both low bone mass and sarcopenia. Low bone mass was defined as T score $\leq-1$ SD below the young adult mean at either femoral neck, lumbar spine, or total hip, considering the Caucasian women aged 20-29years as the reference group [22]. Sarcopenia was considered a low muscle mass plus low muscle strength or low physical performance [23]. The recommended cutoff value for low skeletal muscle mass was $7 \mathrm{~kg} / \mathrm{m}^{2}$ in men [24]. Low muscle strength was considered as handgrip strength $<26 \mathrm{~kg}$ in men and the cutoff value for physical performance was gait speed $<0.8 \mathrm{~m} / \mathrm{s}$ [25].

A history of falling was defined as a self-reported unintentional down on the ground or lower level than the previous one $[26,27]$. All falling that have been occurred during the previous year before the study were included. Hypertension was considered as $\mathrm{SBP} \geq 140 \mathrm{mmHg}$ or $\mathrm{DBP} \geq 90 \mathrm{mmHg}$ or taking any antihypertensive medications [28]. The body mass index (BMI) was calculated as weight $(\mathrm{kg})$ divided by squared height $(\mathrm{m} 2)$. Diabetes was diagnosed with any of these criteria: FPG $\geq 126 \mathrm{mg} / \mathrm{dl}, \mathrm{HbA} 1 \mathrm{C} \geq 6.5 \%$ or taking any anti-diabetic medications [29]. Hypertriglyceridemia was defined as triglyceride level $\geq 150 \mathrm{mg} /$ dl. Hypercholesterolemia and Low HDL-Cholesterol were considered as total cholesterol $\geq 200 \mathrm{mg} / \mathrm{dl}$ and HDL-C $<40 \mathrm{mg} / \mathrm{dl}$, respectively [30]. Lifestyle was categorized to four groups based on the physical activity level as sedentary (1-1.39), low active (1.4-1.59), active (1.6-1.89), and very active (1.9-2.5) [31]. We defined low physical activity, considering the sedentary and low active. High physical activity includes active and very active individuals. Smoking was defined as smoking water pipes or cigarettes at the study time.

\section{Statistical analysis}

Summary statistics were explained as the frequency (percentage) for categorical variables and mean ( \pm standard deviation) for normally distributed continuous variables. Variables with non-normal distribution diagnosed by the Shapiro-Wilk normality test were presented as the median and interquartile range (IQR). We compared the individuals with and without a history of falling for the baseline characteristics using Pearson's Chi-square test for the categorical variables. Independent sample t-test and Mann-Whitney-u test were used for normally and non-normally distributed variables, respectively. Among potential confounding variables including age, education, FPG, SBP, lipid profiles, current smoking, BMI, waist circumference, and physical activity, the best subset included age, SBP, FPG, and hypertriglyceridemia, selected by the Akaike Information Criterion (AIC). We used multivariable fractional polynomials (MFP) to check the non-linearity of predictor - outcome associations [32]. We used the logistic regression model to determine the association of the potential cardio-metabolic variables and history of falling (as dependent variable) in individuals with osteosarcopenia. The interaction terms between age and other risk factors were assessed. The receiver operating characteristic (ROC) curve was used to show the goodness of fit of the final model. All the $p$-values $<0.05$ were considered as statistically significant. Stata statistical package (Stata Statistical Software: Release 14. College Station, TX: StataCorp LP) was used to perform the statistical analyses.

\section{Results}

This study was performed using the data of all osteosarcopenic men $(n=341)$ in BEH program. Among them, 50 (14.7\%) individuals reported a positive history of falling. Table 1 shows the baseline characteristics of the participants by a history of falling. On average, participants with a history of falling were 3 years older than the others with no history of falling (75.9 vs 72.9 years, $P=0.007)$. Systolic Blood Pressure was also significantly different in individuals with and without a history of falling. Hypertriglyceridemia showed a higher prevalence in participants without a history of falling; however, the difference was not statistically significant $(24.4 \%$ vs $12.0 \%$, $P=0.053)$. There was no difference in the mean values of $\mathrm{BMI}$ in patients with and without a history of falling (24.0 vs $23.9, P=0.848$ ).

Table 2 shows the determinants of falling in men with osteosarcomopenia, adjusted for other variables. Falling was significantly associated with age, SBP, FPG level in patients under treatment, and hypertriglyceridemia. As shown, there was a positive association between the presence of falling and 
Table 1 Baseline characteristics of the participants by history of falling; Bushehr Elderly Health BEH) program

\begin{tabular}{|c|c|c|c|}
\hline & $\begin{array}{l}\text { Fall }+ \\
N=50\end{array}$ & $\begin{array}{l}\text { Fall - } \\
N=291\end{array}$ & $P$-value \\
\hline Continuous Variable & Mean (SD) & Mean (SD) & - \\
\hline Age, year & $75.9(7.9)$ & $72.9(7.3)$ & 0.007 \\
\hline Educationa, Year & $6(1-10)$ & $6(0-10)$ & 0.849 \\
\hline $\begin{array}{l}\text { Systolic Blood Pressure, } \\
\mathrm{mmHg}\end{array}$ & $132.1(16.0)$ & $141.1(21.3)$ & 0.005 \\
\hline Body Mass Index, $\mathrm{kg} / \mathrm{m} \wedge 2$ & $24.0(3.9)$ & $23.9(3.3)$ & 0.848 \\
\hline Waist Circumference, cm & $92.3(12.2)$ & $91.9(10.3)$ & 0.799 \\
\hline $\begin{array}{l}\text { Fasting Plasma Glucose }{ }^{a} \text {, } \\
\text { mg/dl }\end{array}$ & $91.5(81.3-131.8)$ & $88(82-100)$ & 0.423 \\
\hline Categorical variables & $\mathrm{N}(\%)$ & $N(\%)$ & - \\
\hline Current smoking & $9(18.0)$ & $72(24.7)$ & 0.301 \\
\hline Diabetes & $19(38.0)$ & $80(27.6)$ & 0.134 \\
\hline Hypertension & $34(68.0)$ & $204(70.1)$ & 0.765 \\
\hline Hypertriglyceridemia & $6(12.0)$ & $71(24.4)$ & 0.053 \\
\hline Hypercholesterolemia & $12(24.0)$ & $70(24.1)$ & 0.993 \\
\hline Low HDL-Cholesterol & $19(38.0)$ & $107(36.8)$ & 0.868 \\
\hline Physical activity & $5(10.0)$ & $41(14.1)$ & 0.611 \\
\hline
\end{tabular}

- Diabetes was defined as FPG $\geq 126 \mathrm{mg} / \mathrm{dl}$, or $\mathrm{HbA} 1 \mathrm{C} \geq 6.5$ or taking antidiabetic medication

- Hypercholesterolemia was defined as total cholesterol $\geq 200 \mathrm{mg} / \mathrm{dl}$

- Low HDL-Cholesterol was defined as HDL-C $<40 \mathrm{mg} / \mathrm{dl}$

- Hypertriglyceridemia was defined as triglyceride $\geq 150 \mathrm{mg} / \mathrm{dl}$

a Due to not normal distribution, median (25th-75th percentile) was reported and $p$-value was estimated using non-parametric test

Table 2 Determinants of falling in men with osteosarcopenia; Bushehr Elderly Health (BEH) program

\begin{tabular}{llll}
\hline & Odds Ratio & $\mathbf{9 5 \%} \mathbf{C l}^{\mathbf{a}}$ & $\boldsymbol{P}^{\text {-value }}$ \\
\hline Age, year & 1.09 & $1.04-1.14$ & $<0.001$ \\
Systolic Blood Pressure, $10 \mathrm{mmHg}$ & 0.74 & $0.62-0.89$ & 0.001 \\
Fasting Plasma Glucose, $10 \mathrm{mg} / \mathrm{dl}$ & 1.14 & $1.06-1.23$ & $<0.001$ \\
Hypertriglyceridemia & 0.33 & $0.12-0.89$ & 0.028 \\
\hline
\end{tabular}

a $\mathrm{Cl}$ Confidence Interval

age $(\mathrm{OR}=1.09$, CI $95 \%=1.04-1.14)$. History of falling was inversely associated with $\mathrm{SBP},(\mathrm{OR}=0.74$, CI $95 \%=0.62-0.89)$. The FPG level was positively related to the history of falling, as a $10 \mathrm{mg} / \mathrm{dl}$ increase in the level of FPG increased the chance of falling by $14 \%(\mathrm{OR}=1.14,95 \% \mathrm{CI}=1.06-1.23)$. Hypertriglyceridemia was inversely associated with falling $(\mathrm{OR}=0.33$, CI $95 \%=0.12$ to 0.89 ).

The ROC curve replicating the discrimination power of the multivariable logistic regression model was presented in Fig. 1. The area under the ROC curve showed a discriminative ability of $74.04 \%$ for the included variables.

\section{Discussion}

The present study examined the association of cardiometabolic risk factors and falling in a population of Iranian osteosarcopenic men. The result of the study showed that age and FPG had a positive association with falls, whereas we observed the inverse association of SBP and TG. The other risk factors were not significantly associated with an increased risk of falling in the osteosarcopenic people.

Considering the high rates of mortality after both falling and fractures, this study aimed to investigate the associates of falling in osteosarcopenic men. Not only a lower rate of correct and timely diagnosis of osteoporosis were reported in men, fewer men take adequate treatment compared to women.

In our study, the presence of falls was strongly correlated with age in osteosarcopenic men. Many documents suggest aging are accompanied by osteoporosis, sarcopenia, and both of them are common diseases that predominantly affect the elderly and considered as risk factors for dysmobility, frailty, falls, fractures, and mortality in older people [33-35].

It has been shown that uncontrolled blood pressure increases the risk of immediate standing balance impairment. Some studies showed the effect of a drop in blood pressure on increasing the rate of falls [36-39]. Our study revealed that SBP (including treated or untreated status) is inversely associated with falling. In line with our project, Klein et al. showed that an increase of SBP by ten $\mathrm{mmHg}$ reduced the risk of falling by $9 \%$ in women [36]. Orthostatic hypotension $(\mathrm{OH})$, as a risk factor for falls, is a common clinical phenomenon in the elderly population and is associated with blood pressure treatment [40]; so, the management of hypertension in the elderly population requires a careful balancing of the benefits and risks of therapy [36-39, 41]. Considering the high prevalence of both osteosarcopenia (34\%) [6] and hypertension $(42 \%)$ in the elderly population [42], comprehensive care for hypertension is needed.

In our study, there was also a remarkable correlation between the FPG level and fall in men with osteosarcopenia. Type 2 diabetes (T2D) causes more falls due to different factors such as peripheral and autonomic neuropathy, retinopathy, microvascular complications, and other comorbidities like obesity [14] and muscle dysfunction [43] with $30 \%$ lower leg muscle strength in diabetics compared to the non-diabetic group [44]. Insulin resistance and glycation end-products (AGEs) accumulation can cause losses in muscle mass and strength, resulting in the sarcopenia and plays an essential role in the interaction between sarcopenia and T2D [45-47]. Another study showed that hypoglycemia increases the risk of falls in diabetic patients due to the decrease in attention, 


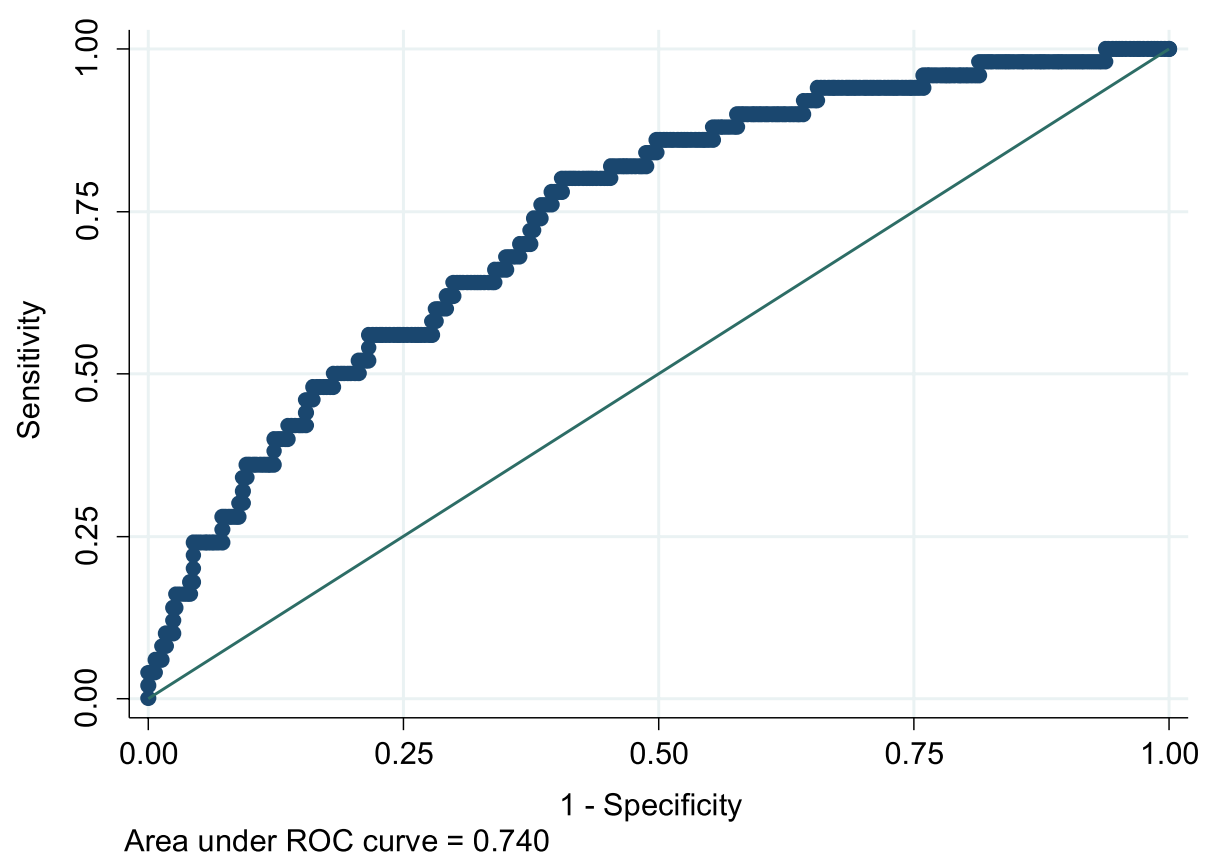

Fig. 1 The receiver operating characteristic (ROC) curve showing the discrimination power of variables correlates to the falling in men with osteosarcopenia

slowing psychomotor speed, and impairment of vascular autonomic nerves [48]. Although many studies showed that diabetes and its complications play essential roles in falling, studies about the direct association between blood sugar and fall were insufficient, especially in osteosarcopenia. Cesare Berra and colleagues also showed that both hypoglycemia $(\mathrm{BS}<70 \mathrm{mg} / \mathrm{dl})$ and hyperglycemia (BS > 200 mg /dl) were significantly associated with increased risk of falls among hospitalized patients [49]. In our study, there was also a remarkable correlation between the FPG level and fall in men with osteosarcopenia. We found that increasing FPG can significantly associate with the history of falling in patient with osteosarcopenia and should be carefully controlled.

In our study, there was no association between falls and BMI in osteosarcopenic men. The result of a metaanalysis revealed that the risk of falling increases in the obese older population aged over 60 years by $16 \%$, compared to the non-obese ones, and that was due to poor lower limb muscle quality, increase foot load, and impaired postural control [15]; however, another study showed that both sarcopenia and obesity have an independent association with fall [50]. Researchers explained that these different results might be due to using various definitions of obesity, such as BMI, waist circumference, or assessment of body fat mass. In the current study, the mean values of BMI were the same in participants with and without a history of falling, resulting in less heterogeneity in the study population, which may explain the lack of association.

We found that hypertriglyceridemia can reduce the chances of falling by almost $60 \%$. To our knowledge, there is no study to show the association between lipid profile and falls in osteosarcopenic patients, while adjusted by other cardiovascular risk factors, TG $>150 \mathrm{mg} / \mathrm{dl}$ showed an inverse association with pre-frailty (OR: 0.61 ) and frailty (OR: 0.49) among hospitalized older adults in Brazil, although these associations were not statistically significant [51]. Low levels of triglycerides might be potential warning signals of problems in nutritional status or rapidly deteriorating health, while more data are needed to clarify the association between triglycerides and falling in the older population.

This research, with a sample from a population-based study, supplied information on factors associated with falling in osteosarcopenic patients. Some limitations should be acknowledged; osteosarcopenia is a newly described syndrome, and comprises of two diseases; so, the results identified can be influenced by the direction and also the power of the association of variables with each of the disease components. Since studies that directly target the osteosarcopenia are scarce, comprehensive comparison with other studies is not entirely possible.

Moreover, our research was a cross-sectional studi $y$, and the result did not interpret any causal relations. 
Further prospective studies are required to clearly explain the leading risk factors of falling in osteosarcopenic patients. Considering the cross-sectional design of the study, the generalizability of the results should be further assessed in other studies with a different population in a larger sample size.

\section{Conclusion}

Age and FPG levels showed a positive association with history of falling in osteosarcopenic men, while an inverse association was detected for SBP and TG. Considering both the role of falling in inducing osteoporotic fractures, and the possible increased risk of fractures in osteosarcopenic patients, and also the higher rate of mortality after falling and fractures in elderly men, comprehensive care is needed to control the cardiometabolic risk factors, especially blood pressure in men with osteosarcopenia.

\section{Abbreviations \\ BEH: Bushehr Elderly Health; AOR: Adjusted Odds Ratio; DXA: Dual X-ray absorptiometry; Cl: Confidence Interval; SBP: Systolic Blood Pressure; FPG: Fasting Plasma Glucose; DBP: Diastolic Blood Pressure; BMI: Body Mass Index; IQR: Interquartile Range; AIC: Akaike Information Criterion; MFP: Multivariable Fractional Polynomials; ROC: Receiver Operating Characteristic Curve; T2D: Type 2 diabetes; TG: Triglyceride.}

\section{Acknowledgements}

The authors would like to express their gratefulness to the staff and researchers of the Bushehr Elderly Health program for their thoughtful contribution.

\section{Authors' contributions}

$\mathrm{NF}, \mathrm{AO}$ and SGh contributed to the conception and design, statistical analysis and interpretation, and drafting the manuscript. ShY, SN, MS, AM, GSh and AHD contributed to the literature review, data cleaning, drafting the manuscript and commented on the manuscript, critically. IN, AA, GhH and BL contributed to interpreting the results and revised the manuscript critically. SGh, $\mathrm{KKh}$, and $\mathrm{RH}$ provided technical advice for analysis and interpreting the results, and critically revised the manuscript. AO supervised the project, contributed to the study design, offered technical advice for statistical analysis, interpreted the results and revised the manuscript critically. All authors finally approved the manuscript to be published.

\section{Funding}

This study used the data from the original study of "Bushehr Elderly Health (BEH) program" that was funded by the "Bushehr University of Medical Sciences" and "Endocrinology and Metabolism Research Institute" affiliated to the Tehran University of Medical Sciences.

\section{Availability of data and materials}

The datasets used and/or analysed during the current study are available from the corresponding author on reasonable request.

\section{Declarations}

\section{Ethics approval and consent to participate}

The Bushehr Elderly Health (BEH) program was approved by the Research Ethics Committee of both Bushehr University of Medical Sciences (code of ethics: B-91-14-2), and Endocrinology \& Metabolism Research Institute (code:IR.TUMS. EMRI.REC.1394.0036). All of the patients signed informed consent according to the medical ethics committee.

\section{Consent for publication}

"Not Applicable".

\section{Competing interests}

The authors declare that they have no competing interests.

\section{Author details}

${ }^{1}$ Osteoporosis Research Center, Endocrinology and Metabolism Clinical Sciences Institute, Tehran University of Medical Sciences, Tehran, Iran. ${ }^{2}$ Department of Epidemiology and Biostatistics, Pasteur Institute of Iran, Tehran, Iran. ${ }^{3}$ Department of Epidemiology, School of Public Health and Safety, Shahid Beheshti University of Medical Science, Tehran, Iran. ${ }^{4}$ Chronic Diseases Research Center, Endocrinology and Metabolism Population Sciences Institute, Tehran University of Medical Sciences, Tehran, Iran. ${ }^{5}$ The Persian Gulf Marine Biotechnology Research Center, The Persian Gulf Biomedical Sciences Research Institute, Bushehr University of Medical Sciences, Bushehr, Iran. ${ }^{6}$ Division of Rheumatology, Department of Internal Medicine, School of Medicine, Bushehr University of Medical Sciences, Bushehr, Iran. ${ }^{7}$ The Persian Gulf Tropical Medicine Research Center, The Persian Gulf Biomedical Sciences Research Institute, Bushehr University of Medical Sciences, Bushehr, Iran. ${ }^{8}$ Deputy for Education, Ministry of health and medical education, Tehran, Iran. ${ }^{9}$ Endocrinology and Metabolism Research Center, Endocrinology and Metabolism Clinical Sciences Institute, Tehran University of Medical Sciences, Tehran, Iran.

Received: 5 May 2021 Accepted: 24 November 2021

Published online: 11 January 2022

\section{References}

1. Binkley N, Buehring B. Beyond FRAX ${ }^{\circledR}$ : It's time to consider "sarco-osteopenia". J Clin Densitom. 2009;4(12):413-6.

2. Kirk B, Al Saedi A, Duque G. Osteosarcopenia: a case of geroscience. Aging Med. 2019;2(3):147-56.

3. Paintin J, Cooper C, Dennison E. Osteosarcopenia. Br J Hosp Med. 2018;79(5):253-8.

4. Yoo J-I, Ha Y-C. Review of epidemiology, diagnosis, and treatment of osteosarcopenia in Korea. J Bone Metab. 2018;25(1):1-7.

5. Huo YR, Suriyaarachchi P, Gomez F, Curcio CL, Boersma D, Muir SW, et al. Phenotype of osteosarcopenia in older individuals with a history of falling. J Am Med Dir Assoc. 2015;16(4):290-5.

6. Fahimfar N, Tajrishi FZ, Gharibzadeh S, Shafiee G, Tanha K, Heshmat R, et al. Prevalence of osteosarcopenia and its association with cardiovascular risk factors in Iranian older people: Bushehr elderly health (BEH) program. Calcif Tissue Int. 2020;106(4):364-70.

7. Hirschfeld H, Kinsella R, Duque G. Osteosarcopenia: where bone, muscle, and fat collide. Osteoporos Int. 2017:28(10):2781-90.

8. Kaji H. Interaction between muscle and bone. J Bone Metab. 2014;21(1):29-40.

9. Teng Z, Zhu Y, Teng Y, Long Q, Hao Q, Yu X, et al. The analysis of osteosarcopenia as a risk factor for fractures, mortality, and falls. Osteoporos Int. 2021:32(11):2173-83.

10. Salech F, Marquez C, Lera L, Angel B, Saguez R, Albala C. Osteosarcopenia predicts falls, fractures, and mortality in Chilean community-dwelling older adults. J Am Med Dir Assoc. 2021;22(4):853-8.

11. Yu R, Leung J, Woo J. Incremental predictive value of sarcopenia for incident fracture in an elderly Chinese cohort: results from the osteoporotic fractures in men (MrOs) study. J Am Med Dir Assoc. 2014;15(8):551-8.

12. Muir SW, Gopaul K, Montero Odasso MM. The role of cognitive impairment in fall risk among older adults: a systematic review and meta-analysis. Age Ageing. 2012;41(3):299-308

13. Kwan MMS, Close JC, Wong AKW, Lord SR. Falls incidence, risk factors, and consequences in Chinese older people: a systematic review. J Am Geriatr Soc. 2011;59(3):536-43

14. Liao K-C, Pu S-J, Lin C-H, Chang H-J, Chen Y-J, Liu M-S. Association between the metabolic syndrome and its components with falls in community-dwelling older adults. Metab Syndr Relat Disord. 2012;10(6):447-51.

15. Neri SGR, Oliveira JS, Dario AB, Lima RM, Tiedemann A. Does obesity increase the risk and severity of falls in people aged 60 years and older? A systematic review and meta-analysis of observational studies. J Gerontol Ser A. 2020;75(5):952-60.

16. Ferlin A, Migliaccio S. Male Osteoporosis: Gender Differences In Pathophysiology, Clinical Aspects, Diagnosis and Treatment. 1st ed. 2020. https://lib.ugent.be/catalog/ebk01:4100000011435779. 
17. Rao SS, Budhwar N, Ashfaque A. Osteoporosis in men. Am Fam Physician. 2010;82(5):503-8.

18. Varenna M, Manara M, Galli L, Binelli L, Zucchi F, Sinigaglia L. The association between osteoporosis and hypertension: the role of a low dairy intake. Calcif Tissue Int. 2013;93(1):86-92.

19. Migliaccio S, Greco EA, Fornari R, Donini LM, Lenzi A. Is obesity in women protective against osteoporosis? Diabetes Metab Syndr Obes. 2011;4:273.

20. Du Y, Oh C, No J. Associations between sarcopenia and metabolic risk factors: a systematic review and meta-analysis. J Obes Metab Syndr. 2018;27(3):175.

21. Shafiee G, Ostovar A, Heshmat R, Darabi H, Sharifi F, Raeisi A, et al. Bushehr elderly health (BEH) programme: study protocol and design of musculoskeletal system and cognitive function (stage II). BMJ Open. 2017;7(8):e013606.

22. Kanis JA, Adachi JD, Cooper C, Clark P, Cummings SR, Diaz-Curiel M, et al. Standardising the descriptive epidemiology of osteoporosis: recommendations from the epidemiology and quality of life working group of IOF. Osteoporos Int. 2013:24(11):2763-4.

23. Cruz-Jentoft AJ, Baeyens JP, Bauer JM, Boirie Y, Cederholm T, Landi F, et al. Sarcopenia: European consensus on definition and diagnosisReport of the European working group on sarcopenia in older PeopleA. J. CruzGentoft et al. Age Ageing. 2010;39(4):412-23.

24. Shafiee G, Ostovar A, Heshmat R, Keshtkar AA, Sharifi F, Shadman Z, et al. Appendicular skeletal muscle mass reference values and the peak muscle mass to identify sarcopenia among Iranian healthy population. Int J Prev Med. 2018;9:25.

25. Chen L-K, Liu L-K, Woo J, Assantachai P, Auyeung T-W, Bahyah KS, et al. Sarcopenia in Asia: consensus report of the Asian working Group for Sarcopenia. J Am Med Dir Assoc. 2014;15(2):95-101.

26. Pasquetti P, Apicella L, Mangone G. Pathogenesis and treatment of falls in elderly. Clin Cases Miner Bone Metab. 2014:11(3):222.

27. Rubenstein LZ, Robbins AS, Josephson KR, Schulman BL, Osterweil D. The value of assessing falls in an elderly population: a randomized clinical trial. Ann Intern Med. 1990;113(4):308-16.

28. Williams B, Mancia G, Spiering W, Agabiti Rosei E, Azizi M, Burnier M, et al. 2018 ESC/ESH guidelines for the management of arterial hypertension: the task force for the management of arterial hypertension of the European Society of Cardiology (ESC) and the European Society of Hypertension (ESH). Eur Heart J. 2018;39(33):3021-104.

29. Association AD. Diagnosis and classification of diabetes mellitus. Diabetes Care. 2014;37(Supplement 1):S81-90.

30. Grundy SM, Cleeman JI, Daniels SR, Donato KA, Eckel RH, Franklin BA, et al. Diagnosis and management of the metabolic syndrome: an American Heart Association/National Heart, Lung, and Blood Institute scientific statement. Circulation. 2005;112(17):2735-52.

31. Mahan LK, Raymond JL. Krause's food \& the nutrition care process-ebook: Elsevier Health Sciences; 2016.

32. Royston P, Sauerbrei W. Building multivariable regression models with continuous covariates in clinical epidemiology. Methods Inf Med. 2005;44(04):561-71

33. Brotto $\mathrm{M}$, Bonewald L. Bone and muscle: interactions beyond mechanical. Bone. 2015;80:109-14.

34. Laurent MR, Dedeyne L, Dupont J, Mellaerts B, Dejaeger M, Gielen E. Agerelated bone loss and sarcopenia in men. Maturitas. 2019;122:51-6.

35. Szlejf C, Parra-Rodriguez L, Rosas-Carrasco O. Osteosarcopenic obesity: prevalence and relation with frailty and physical performance in middleaged and older women. J Am Med Dir Assoc. 2017;18(8):733.e731-5.

36. Klein D, Nagel G, Kleiner A, Ulmer H, Rehberger B, Concin H, et al. Blood pressure and falls in community-dwelling people aged 60 years and older in the VHM\&PP cohort. BMC Geriatr. 2013:13:50.

37. Berlowitz DR. Hypertension treatment and falls: should we be concerned? J Gen Intern Med. 2014;29(12):1577-8

38. Tinetti ME, Han L, Lee DS, McAvay GJ, Peduzzi P, Gross CP, et al. Antihypertensive medications and serious fall injuries in a nationally representative sample of older adults. JAMA Intern Med. 2014;174(4):588-95.

39. Margolis KL, Palermo L, Vittinghoff E, Evans GW, Atkinson HH, Hamilton $\mathrm{BP}$, et al. Intensive blood pressure control, falls, and fractures in patients with type 2 diabetes: the ACCORD trial. J Gen Intern Med. 2014;29(12):1599-606.
40. Kamaruzzaman S, Watt H, Carson C, Ebrahim S. The association between orthostatic hypotension and medication use in the British Women's heart and health study. Age Ageing. 2010;39(1):51-6.

41. Macdonald JB. The role of drugs in falls in the elderly. Clin Geriatr Med. 1985; (3):621-36

42. Oori MJ, Mohammadi F, Norozi K, Fallahi-Khoshknab M, Ebadi A, Gheshlagh RG. Prevalence of HTN in Iran: Meta-analysis of published studies in 2004-2018. Curr Hypertens Rev. 2019;15(2):113-22.

43. Kelley DE, He J, Menshikova EV, Ritov VB. Dysfunction of mitochondria in human skeletal muscle in type 2 diabetes. Diabetes. 2002;51(10):2944-50.

44. Park SW, Goodpaster BH, Strotmeyer ES, Kuller LH, Broudeau R, Kammerer $C$, et al. Accelerated loss of skeletal muscle strength in older adults with type 2 diabetes: the health, aging, and body composition study. Diabetes Care. 2007;30(6):1507-12.

45. Mesinovic J, Zengin A, De Courten B, Ebeling PR, Scott D. Sarcopenia and type 2 diabetes mellitus: a bidirectional relationship. Diabetes Metab Syndr Obes. 2019;12:1057.

46. Corcoran MP, Lamon-Fava S, Fielding RA. Skeletal muscle lipid deposition and insulin resistance: effect of dietary fatty acids and exercise. Am J Clin Nutr. 2007;85(3):662-77.

47. Russell ST, Rajani S, Dhadda RS, Tisdale MJ. Mechanism of induction of muscle protein loss by hyperglycaemia. Exp Cell Res. 2009;315(1):16-25.

48. Chiba Y, Kimbara Y, Kodera R, Tsuboi Y, Sato K, Tamura Y, et al. Risk factors associated with falls in elderly patients with type 2 diabetes. J Diabetes Complicat. 2015;29(7):898-902.

49. Berra C, De Fazio F, Azzolini E, Albini M, Zangrandi F, Mirani M, et al. Hypoglycemia and hyperglycemia are risk factors for falls in the hospital population. Acta Diabetol. 2019;56(8):931-8.

50. Baumgartner RN. Body composition in healthy aging. Ann N Y Acad Sci. 2000;904(1):437-48.

51. Tavares DMS, Colamego CG, Pegorari MS, Ferreira PCS, Dias FA, Bolina AF. Cardiovascular risk factors associated with frailty syndrome among hospitalized elderly people: a cross-sectional study. Sao Paulo Med J. 2016;134(5):393-9.

\section{Publisher's Note}

Springer Nature remains neutral with regard to jurisdictional claims in published maps and institutional affiliations.

Ready to submit your research? Choose BMC and benefit from

- fast, convenient online submission

- thorough peer review by experienced researchers in your field

- rapid publication on acceptance

- support for research data, including large and complex data types

- gold Open Access which fosters wider collaboration and increased citations

- maximum visibility for your research: over $100 \mathrm{M}$ website views per year

At BMC, research is always in progress.

Learn more biomedcentral.com/submissions 